\title{
Deforestasi di KabUPATEN TELUK BinTUNi Provinsi Papua Barat
}

\section{DEFORESTATION IN BINTUNI BAY REgENCY West Papua Province}

\author{
Saremay Max Romario Sawaki ${ }^{1, *}$, Hendri ${ }^{2}$, Soetjipto Moeljono ${ }^{3}$ \\ ${ }^{1}$ Pascasarjana Universitas Papua \\ ${ }^{2,3}$ Fakultas Kehutanan Universitas Papua \\ Jl. Gunung Salju, Amban - Manokwari, Indonesia 98314
}

Dikirim: 6 Januari 2020; Disetujui: 30 Mei 2020; Diterbitkan: 29 Juni 2020

\section{Inti Sari}

Deforestasi merupakan hilangnya tutupan hutan atau perubahan hutan yang dikonversi dari hutan menjadi bukan hutan. Deforestasi terencana merupakan deforestasi di areal izin konsesi dan izin konversi lahan pada kawasan hutan, sedangkan deforestasi tidak terencana merupakan deforestasi yang terjadi di luar areal izin konsesi dan izin konversi lahan pada kawasan hutan. Penelitian ini bertujuan untuk mengetahui: 1) Luas deforestasi selama 27 tahun sesuai time series atau periode data tutupan lahan tahun 1990 sampai 2017; 2) menghitung jumlah emisi karbon dioksida (CO2) yang diakibatkan adanya deforestasi; 3) menghitung potensi kerugian ekonomi atau kerugian finansial sebagai dampak deforestasi selama 27 tahun. Penelitian ini menggunakan metode analisis data kuantitatif dari data peta tutupan lahan kementerian lingkungan hidup dan kehutanan tahun 1990 sampai tahun 2017 dan hasil penelitian menunjukkan luas hutan yang mengalami deforestasi selama periode 27 tahun adalah sebesar 22.767 hektar. Deforestasi yang terjadi $76,7 \%$ adalah sebagai dampak dari deforestasi terencana selama 27 tahun ini, diperkirakan jumlah emisi karbon dioksida yang dihasilkan adalah sebesar 7.686.155 ton CO2/ha atau setara dengan potensi kerugian ekonomi sebesar Rp381.499.992.777,-. Hasil penelitian ini diharapkan dapat menjadi acuan bagi Pemerintah Kabupaten Teluk Bintuni untuk mengambil kebijakan dalam pengembangan dan pembangunan berkelanjutan.

Kata Kunci: Emisi Karbon Dioksida, Potensi Kerugian Ekonomi, Deforestasi, Kabupaten Teluk Bintuni.

\begin{abstract}
Deforestation is the conservation forested area to non-forested area. Planned deforestation is planned forest conservation or deforestation from forested area to non-forested area, while unplanned deforestation is deforestation outside designated planned conversion area. This was designed to examine 1) deforestation during 27 years from 1990 to 2017 in the Bintuni Bay Regency; 2) estimate Carbon dioxide (CO2) emissions from deforestation; and 3) estimate the potential economic loss due to deforestation. This study shows that about 22,783 ha forest have been declared during this period of which about $76.7 \%$ occurred within concession area. It estimated about 7,686,155 tons of CO2/ha carbon dioxide was produced or equal to Rp381,499,992,777. It is hoped the future, government development policies would consider other values such as carbon trade and environmental services.
\end{abstract}

Keywords: Carbon dioxide Emission, Deforestation, Estimate Carbon Values, Bintuni Bay Regency.

* Korespondensi Penulis

Telepon : +62 81344922130

Email : saremaysawaki@gmail.com
(C) 2020 Saremay Max Romario Sawaki, Hendri, Soetjipto Moeljono Ciptaan disebarluaskan di bawah Lisensi Creative Commons Atribusi-NonKomersial-BerbagiSerupa 4.0 Internasional. 


\section{Pendahuluan}

Deforestasi merupakan hilangnya tutupan hutan atau perubahan hutan yang dikonversi dari hutan menjadi bukan hutan, misalnya hutan menjadi pemukiman, perkebunan, dan lain sebagainya. Deforestasi terencana merupakan deforestasi yang terjadi di dalam areal izin konsesi dan konversi lahan pada kawasan hutan, sedangkan deforestasi tidak terencana merupakan deforestasi yang terjadi di luar areal izin konsesi dan konversi lahan pada kawasan hutan. Deforestasi secara spasial dan kuantifikasi eksplisit sementara di Provinsi Papua dan Papua Barat adalah \pm 261 ribu ha dari tahun 2000 hingga 2012 (Margono et al., 2014). Luas hutan di Kabupaten Teluk Bintuni adalah \pm 1.806 .601 ha menurut hasil analisis peta batas administrasi Kabupaten Teluk Bintuni yang di-overlay dengan peta luas kawasan hutan di Provinsi Papua Barat pada Keputusan Menteri Kehutanan RI Nomor SK.783/Menhut-II/2014 tanggal 22 September 2014 tentang Kawasan Hutan Provinsi Papua Barat. Luas hutan tersebut dapat mengalami perubahan akibat deforestasi. Deforestasi yang terjadi di Kabupaten Teluk Bintuni dalam kurun waktu hanya lima tahun, periode tahun 2012 sampai 2017 adalah sebesar 3.095 ha (Badan Pemantapan Kawasan Hutan Wilayah XVII, 2017). Oleh karena itu, perlu adanya penelitian mengenai luas deforestasi di Kabupaten Teluk Bintuni periode tahun 1990 sampai 2017. Penelitian ini bertujuan untuk mengetahui: 1) luas deforestasi hutan selama 27 tahun di Kabupaten Teluk Bintuni; 2) menghitung jumlah emisi karbon dioksida akibat deforestasi; dan 3) menghitung potensi kerugian ekonomi akibat deforestasi. Hasil penelitian ini diharapkan dapat menjadi acuan bagi Pemerintah Kabupaten Teluk Bintuni dalam pengelolaan hutan sebagai bagian dalam pengembangan dan pembangunan berkelanjutan.

\section{Metode}

Penelitian ini dilakukan di Kabupaten Teluk Bintuni, Provinsi Papua Barat. Metode yang digunakan adalah metode analisis data kuantitatif deforestasi dan data yang diperoleh disajikan dalam bentuk tabel dan gambar. Alat yang digunakan dalam penelitian ini adalah software ArcMap versi 10.5. Bahan data yang digunakan adalah peta tutupan lahan periode tahun 1990 sampai 2017 (Badan Pemantapan Kawasan Hutan Wilayah XVII, 2017) yang disesuaikan menurut Intergovernmental Panel on Climate Change (IPCC), peta batas wilayah administrasi kabupaten Teluk Bintuni (BAPPEDA Kabupaten Teluk Bintuni, 2014), faktor emisi karbon (KLHK, 2016), dan acuan harga 1 tonC/ha menurut Peraturan Menteri Kehutanan Republik Indonesia Nomor P. 36/ Menhut-II/2009.

\section{A. Prosedur Penelitian}

Data yang dikumpulkan berupa data shapefile (shp.) yang bersumber dari Badan Perencanaan Pembangunan Daerah Kabupaten Teluk Bintuni, Balai Pemantapan Kawasan Hutan Wilayah XVII Manokwari Kementerian Lingkungan Hidup dan Kehutanan dan UPT Geospasial UNIPA/PPIDS.

\section{B. Kodifikasi}

Kodifikasi dilakukan pada setiap kelas tipe penutupan lahan Provinsi Papua Barat berdasarkan kodifikasi yang ditetapkan oleh Kementerian Lingkungan Hidup dan Kehutanan dalam Peraturan Direktur Jenderal Planologi Kehutanan tanggal 26 Mei 2015 No. P.1/VII-IPSDH/2015 tentang Pedoman Pemantauan Penutupan Lahan yang dimodifikasi berdasarkan Intergovernmental Panel of Climate Changes (IPCC).

\section{Sistem Koordinat Semua Data Peta Disamakan dan Overlay}

Semua sistem koordinat peta tematik harus dalam format yang sama yaitu format 
Tabel 1.

Kode Penutupan Lahan

\begin{tabular}{|c|c|c|c|c|}
\hline No & Kode & Penutupan Lahan & Singkatan & IPCC \\
\hline 1 & 2001 & Hutan Lahan Kering Primer & $\mathrm{Hp}$ & Forestland \\
\hline 2 & 2004 & Hutan Mangrove Primer & $\mathrm{Hmp}$ & Forestland \\
\hline 3 & 2005 & Hutan Rawa Primer & Hrp & Forestland \\
\hline 4 & 2002 & Hutan Lahan Kering Sekunder & $\mathrm{Hs}$ & Forestland \\
\hline 5 & 20041 & Hutan Mangrove Sekunder & $\mathrm{Hms}$ & Forestland \\
\hline 6 & 20051 & Hutan Rawa Sekunder & Hrs & Forestland \\
\hline 7 & 2006 & Hutan Tanaman & $\mathrm{Ht}$ & Forestland \\
\hline 8 & 2007 & Semak Belukar & B & Grassland \\
\hline 9 & 20071 & Semak Belukar Rawa & $\mathrm{Br}$ & Grassland \\
\hline 10 & 20091 & Pertanian Lahan Kering & $\mathrm{Pt}$ & Cropland \\
\hline 11 & 20092 & Pertanian Lahan Kering Bercampur Semak & $\mathrm{Pc}$ & Cropland \\
\hline 12 & 20093 & Sawah & Sw & Cropland \\
\hline 13 & 20094 & Tambak & $\mathrm{Tm}$ & Otherland \\
\hline 14 & 5001 & Tubuh Air & A & Wetland \\
\hline 15 & 50011 & Rawa & $\mathrm{Rw}$ & Wetland \\
\hline 16 & 2012 & Permukiman & $\mathrm{Pm}$ & Settlement \\
\hline 17 & 20121 & Bandara & Bdr & Otherland \\
\hline 18 & 20122 & Transmigrasi & $\operatorname{Tr}$ & Cropland \\
\hline 19 & 2014 & Tanah Terbuka & $\mathrm{T}$ & Otherland \\
\hline 20 & 20141 & Pertambangan & $\mathrm{Tb}$ & Otherland \\
\hline 21 & 2010 & Perkebunan & $\mathrm{Pk}$ & Cropland \\
\hline 22 & 3000 & Savana & s & Grassland \\
\hline 23 & 2500 & Awan & $A w$ & \\
\hline
\end{tabular}

Sumber: Kementerian Lingkungan Hidup dan Kehutanan (2015) yang dimodifikasi berdasarkan Intergovernmental Panel on Climate Change (IPCC)

data shapefile (shp) agar mempermudah proses analisis data spasial. Sedangkan overlay adalah salah satu proses pada geoprocessing yang bertujuan untuk tumpang tindih peta-peta tematik yang sudah memiliki koordinat sistem dan nilai atribut yang sama untuk mempermudah proses analisis data.

\section{Dissolve}

Dissolve merupakan salah satu proses pada geoprocessing yang bertujuan untuk menyatukan feature yang memiliki nilai atribut yang sama, yaitu menyatukan semua polygon dan menyederhanakannya menjadi satu (1) polygon. 


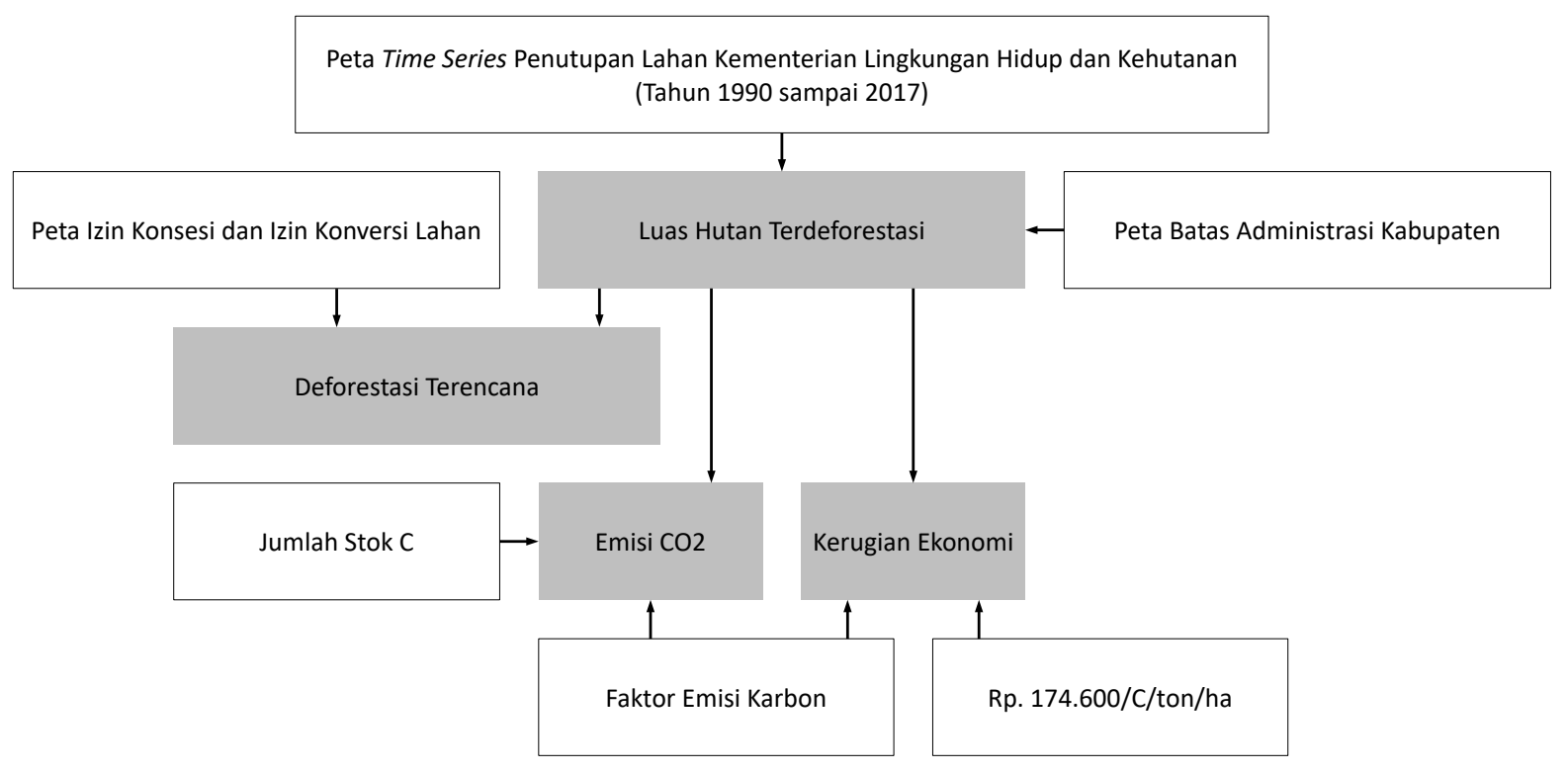

Gambar 1. Alur Analisis Data

\section{Hasil dan Pembahasan}

\section{A. Deforestasi Hutan}

Kabupaten Teluk Bintuni merupakan salah satu Kabupaten yang sangat kaya sumber daya alam, baik sumber daya alam yang ada di laut maupun di darat. Oleh karena itu, Pemerintah Kabupaten Teluk Bintuni melakukan pengembangan baik di bidang investasi dan infrastruktur. Hal ini secara langsung mengakibatkan kebutuhan lahan yang semakin meningkat sehingga menjadi ancaman bagi luas hutan yang ada di Kabupaten Teluk Bintuni. Deforestasi merupakan salah satu dampak yang terjadi dari kegiatan pembangunan.

Gambar 2 merupakan peta tutupan lahan kabupaten Teluk Bintuni pada tahun 1990. Sementara, peta tutupan lahan pada kabupaten tersebut pada tahun 2017 disajikan pada Gambar 3. Terlihat bahwa, walaupun tidak cukup besar luasannya dari luas tutupan hutan secara keseluruhan namun telah terjadi perubahan tutupan lahan hutan di Kabupaten Teluk Bintuni.

Gambar 4 menunjukkan bahwa dalam 27 tahun forestland mengalami penurunan luas sebesar 22.768 ha atau sebesar $1 \%$ dari luas hutan. Penurunan luasan rata-rata per tahun adalah sebesar 843 ha/tahun. Persentase perbandingan perubahan antara hutan (forestland) dan nonhutan (grassland, cropland, wetland, settlement, dan otherland) dapat dilihat pada Tabel 1.

Tabel 2 menunjukkan bahwa perubahan forestland menjadi grassland seluas $8.318 \mathrm{ha}$, cropland 12.169 ha, settlement 982 ha, otherland 1.213 ha dan wetland 86 ha. Cropland menjadi yang terbesar perubahannya hal ini dikarenakan hutan dijadikan sebagai lahan perkebunan untuk peningkatan ekonomi dan transmigrasi dalam pertambahan penduduk di Kabupaten Teluk Bintuni.

Tutupan lahan di Kabupaten Teluk Bintuni mengalami penurunan luasan yang tidak cukup besar dalam rentang waktu 27 tahun. Penurunan yang terjadi adalah sebesar 21.869 ha, yaitu dari 1.847.469 ha (93\%) pada tahun 1990 menjadi 1.825 .600 ha (92\%) pada tahun 2017. Sehingga dapat disimpulkan bahwa tutupan hutan di Kabupaten Teluk Bintuni masih baik karena selama 27 tahun hanya mengalami penurunan atau perubahan sebesar $1 \%$.

Peningkatan luas lahan hutan yang deforestasi juga diakibatkan adanya kawasan 


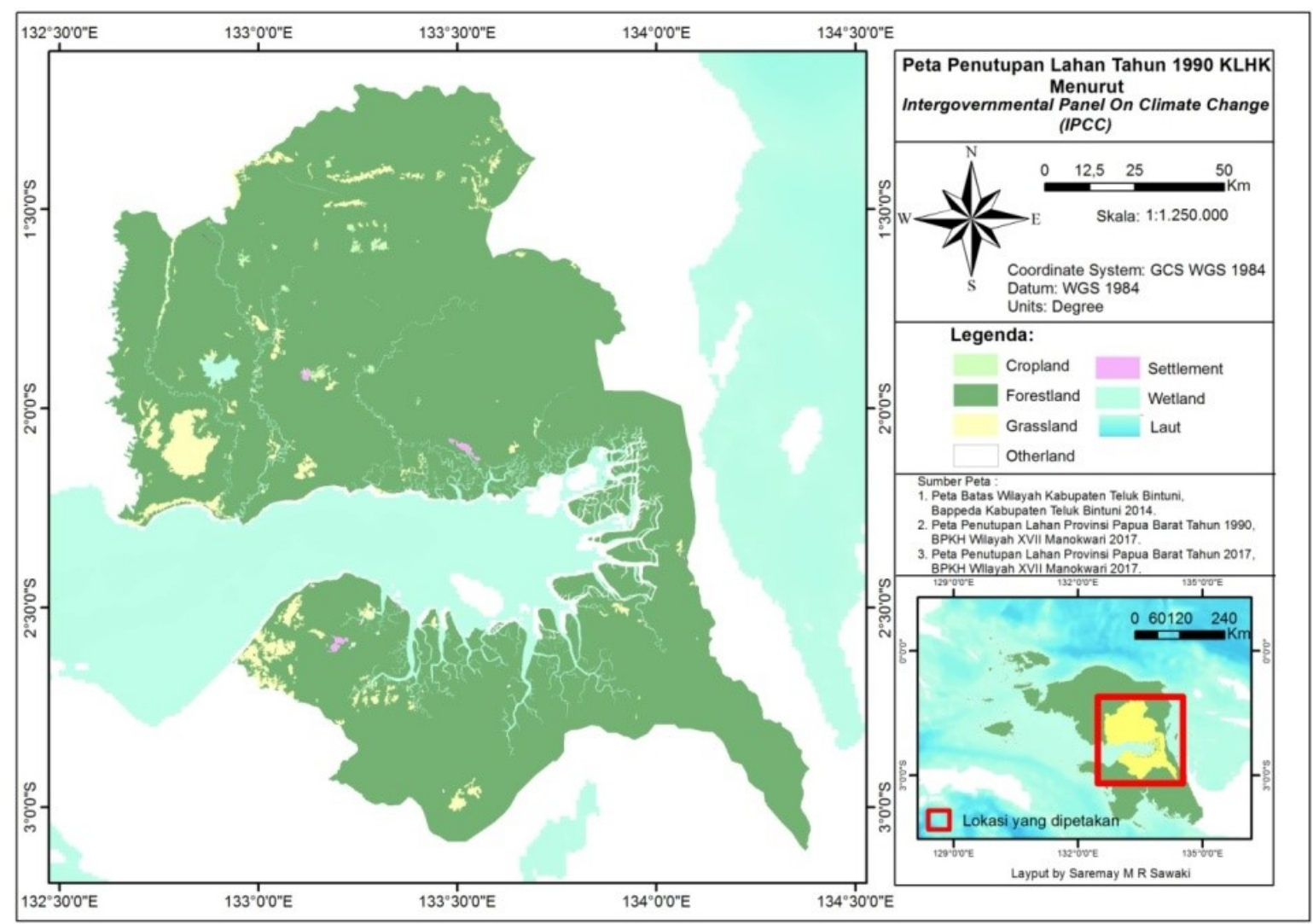

Gambar 2. Peta Penutupan Lahan KLHK Tahun 1990 menurut Intergovernmental Panel on Climate Change (IPCC)

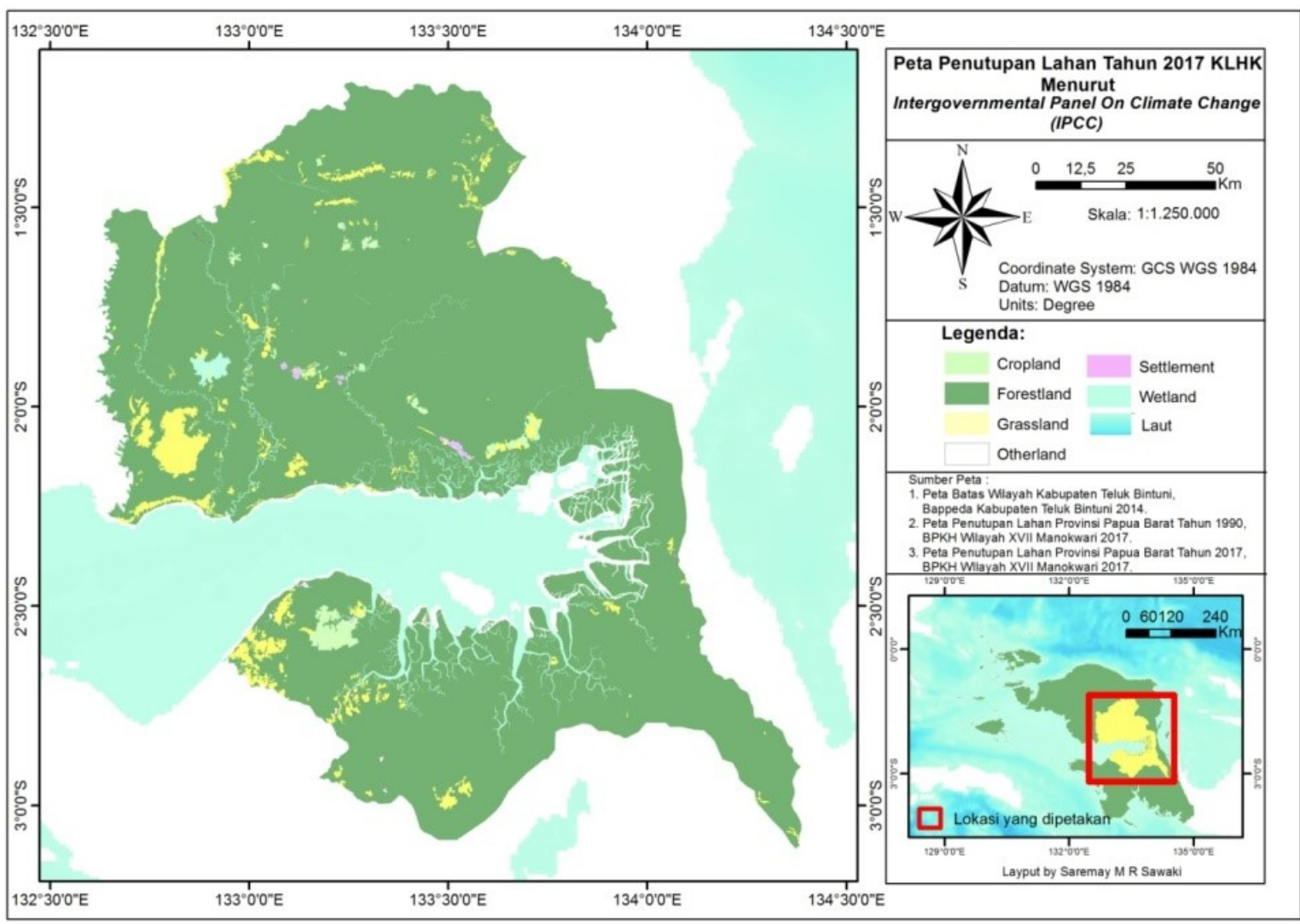

Gambar 3. Peta Penutupan Lahan KLHK Tahun 2017 menurut Intergovernmental Panel on Climate Change (IPCC) 
Tabel 2.

Perubahan Tutupan Lahan Tahun 1990 sampai 2017 menurut Intergovernmental Panel on Climate Change (IPCC)

\begin{tabular}{lrrrrrr} 
Tutupan Lahan & Grassland & Cropland & Settlement & Otherland & Wetland & Luas ha \\
\hline Forestland & 8.318 & 12.169 & 982 & 1.213 & 86 & $\mathbf{2 2 . 7 6 8}$ \\
\hline
\end{tabular}

Sumber:Kementerian Lingkungan Hidup dan Kehutanan (2017)

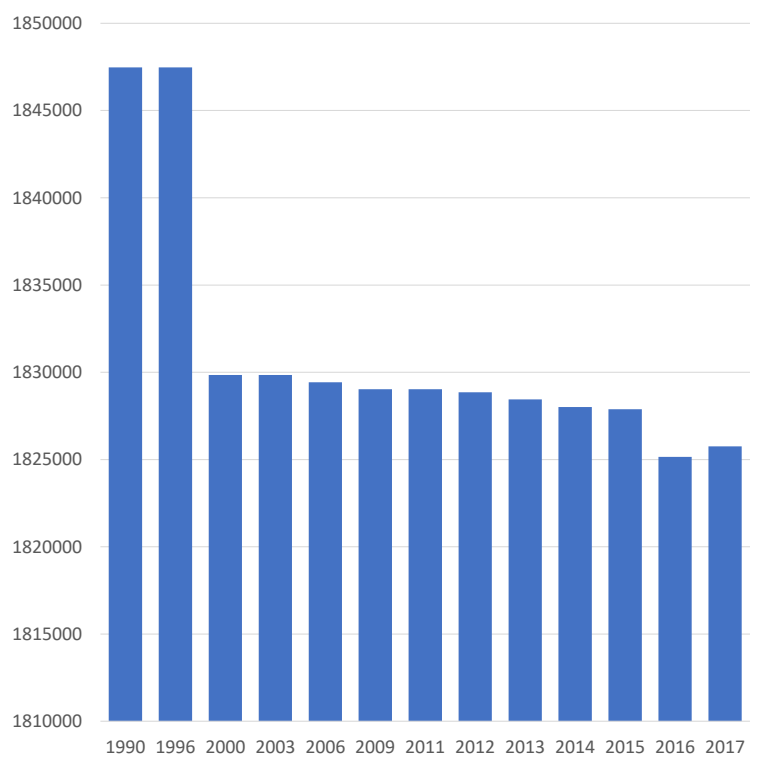

Gambar 4. Tren Perubahan Tutupan Lahan Hutan Tahun 1990 2017 di Kabupaten Teluk Bintuni

izin konsesi dan izin konversi lahan di Kabupaten Teluk Bintuni. Tabel 3 menunjukkan data beberapa perusahaan yang memiliki izin konsesi dan konversi lahan di Kabupaten Teluk Bintuni dan luas deforestasi hutan sebagai dampak aktivitas usahanya. Deforestasi terencana ini adalah sebesar 17.473 ha. Sementara itu, deforestasi yang tidak terencana karena berada di luar kawasan izin konsesi dan konversi lahan sebesar 5.293 ha. Oleh itu, dapat disimpulkan bahwa deforestasi yang terjadi pada kawasan hutan di kabupaten Teluk Bintuni adalah akibat deforestasi terencana.

\section{B. Jumlah Stok Karbon dan Potensi Emisi Karbon Dioksida di Kabupaten Teluk Bintuni}

Jumlah stok karbon atau cadangan karbon yang ada di Kabupaten Teluk Bintuni dihitung dengan menggunakan rumus "Stok Karbon Tahunan $=$ Data Aktivitas $\times$ Stok Karbon Per
Tabel 3.

Deforestasi Terencana pada Perizinan Konsesi dan Konversi di Kabupaten Teluk Bintuni

\begin{tabular}{|c|c|}
\hline Nama Perusahaan & Luas (ha) \\
\hline Alam Setiatama Jaya & 21 \\
\hline Antarnusa Persada Semesta & 29 \\
\hline Bintuni Utama Murni & 332 \\
\hline Bukit Alam Mandiri & 160 \\
\hline Ciptalink Sejahtera & 1.565 \\
\hline Dua Sekawan Jaya & 11 \\
\hline Dzarbasch Indonesia & 108 \\
\hline Inti Citra Mandiri & 118 \\
\hline Irja Tambang Perkasa & 23 \\
\hline Kesatuan Mas Abadi & 2.137 \\
\hline Kurniatama Sejahtera & 292 \\
\hline Lintas Wiguna Lestari & 1.331 \\
\hline Lumika Griya & 33 \\
\hline Manokwari Mandiri & 101 \\
\hline Mitra Pembangunan Global & 28 \\
\hline Muturi Bara Perkasa & 322 \\
\hline Papua Kyriake Hemera & 8 \\
\hline Papua Satya Kencana & 132 \\
\hline Sele Raya & 838 \\
\hline Sinar Bara Papua Cemerlang & 27 \\
\hline Sinar Global & 182 \\
\hline Subur Karunia Raya & 376 \\
\hline Teluk Bintuni Mina Agro K & 495 \\
\hline Tomafed Karya Mandiri & 656 \\
\hline Varita Majutama & 3.257 \\
\hline Varita Majutama 3 & 11 \\
\hline Varita Majutama 4 & 4.201 \\
\hline Wana Galang Utama & 400 \\
\hline Wana Irian Perkasa & 26 \\
\hline $\begin{array}{l}\text { Wapoga Mutiara Timber Unit I } \\
\text { (Wijaya Sentosa) }\end{array}$ & 117 \\
\hline Wukirasari & 5 \\
\hline Yotefa Sarana Timber & 130 \\
\hline Total Luas (ha) & 17.473 \\
\hline \multicolumn{2}{|c|}{$\begin{array}{l}\text { Sumber: WebGIS Kementerian Lingkungan Hidup dan Kehutanan } \\
\text { (2014) dan Data Kompilasi dan verifikasi SKPD Terkait } \\
\text { seluruh Kabupaten di Provinsi Papua Barat (2014) }\end{array}$} \\
\hline
\end{tabular}


Tabel 4.

Jumlah Stok Karbon Per Tutupan Lahan Tahun 2017 di Kabupaten Teluk Bintuni

\begin{tabular}{|c|c|c|c|c|}
\hline Kode & PL KLHK & Luas (ha) & Faktor Emisi C (tonC/ha) & Jumlah Stok C (tonC/ha) \\
\hline 5001 & A & 53.348 & 0 & 0 \\
\hline 2007 & B & 32.449 & 30 & 973.458 \\
\hline 20121 & Bdr & 60 & 0 & 0 \\
\hline 20071 & $\mathrm{Br}$ & 31.945 & 30 & 958.352 \\
\hline 2004 & $\mathrm{Hmp}$ & 141.573 & 270 & 38.224 .618 \\
\hline 20041 & $\mathrm{Hms}$ & 71.239 & 120 & 8.548 .692 \\
\hline 2001 & $\mathrm{Hp}$ & 689.115 & 112.377 & 77.440 .680 \\
\hline 2005 & Hrp & 311.779 & 83.036 & 25.888 .912 \\
\hline 20051 & Hrs & 43.386 & 68.479 & 2.971 .053 \\
\hline 2002 & $\mathrm{Hs}$ & 620.876 & 84.788 & 52.642 .868 \\
\hline 20092 & Pc & 4.593 & 30 & 137.802 \\
\hline 2010 & $\mathrm{Pk}$ & 9.916 & 63 & 624.711 \\
\hline 2012 & $\mathrm{Pm}$ & 3.717 & 5 & 18.585 \\
\hline 20091 & $\mathrm{Pt}$ & 169 & 10 & 1.689 \\
\hline 3000 & S & 16.984 & 4.5 & 76.428 \\
\hline 2014 & T & 1.360 & 2.5 & 3.400 \\
\hline 20141 & $\mathrm{~Tb}$ & 428 & 0 & 0 \\
\hline 20122 & $\operatorname{Tr}$ & 3.914 & 10 & 39.138 \\
\hline \multicolumn{2}{|c|}{ Total (ha) } & 2.036 .852 & & 208.550 .386 \\
\hline
\end{tabular}

Sumber: Kementerian Lingkungan Hidup dan Kehutanan (2017)

Keterangan: Hp = Hutan Primer; Hs = Hutan Sekunder; Hmp = Hutan Mangrover Primer; Hrp = Hutan Rawa Primer; Hms = Hutan Mangrove Sekunder; Hrs = Hutan Rawa Sekunder; $\mathrm{B}=$ Semak Belukar; $\mathrm{Br}=$ Semak Belukar Rawa; $\mathrm{Pt}=$ Pertnian Lahan Kering; Pc = Pertanian Lahan Kering Bercampur Semak; Sw = Sawah; Tm = Tambak; A = Tubuh Air; Pm = Pemukiman; Bdr = Bandara; $\mathrm{Tr}+$ Transmigrasi $\mathrm{T}+$ Tanah Terbuka; $\mathrm{Tb}=$ Pertambangan; $\mathrm{Pk}=$ Perkebunan $\mathrm{S}=$ Savana.

Tutupan Lahan atau faktor emisi karbon" (Kementerian Lingkungan Hidup dan Kehutanan, 2015).

Tabel 4 menunjukkan jumlah stok karbon tahun 2017 di Kabupaten Teluk Bintuni berdasarkan data tutupan lahan tahun 2017 dari Kementerian Lingkungan Hidup dan Kehutanan sebesar 208.550.386 tonC/ 2.036.852 ha. 


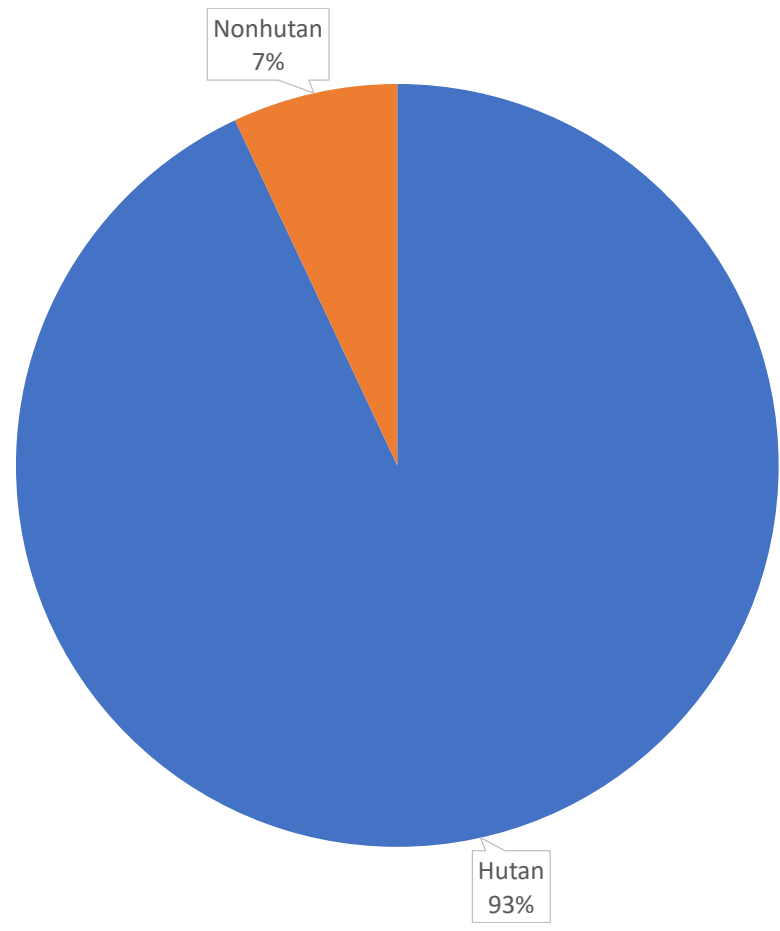

Gambar 5. Persentase (\%) Penutupan Lahan Hutan dan Nonhutan Tahun 1990

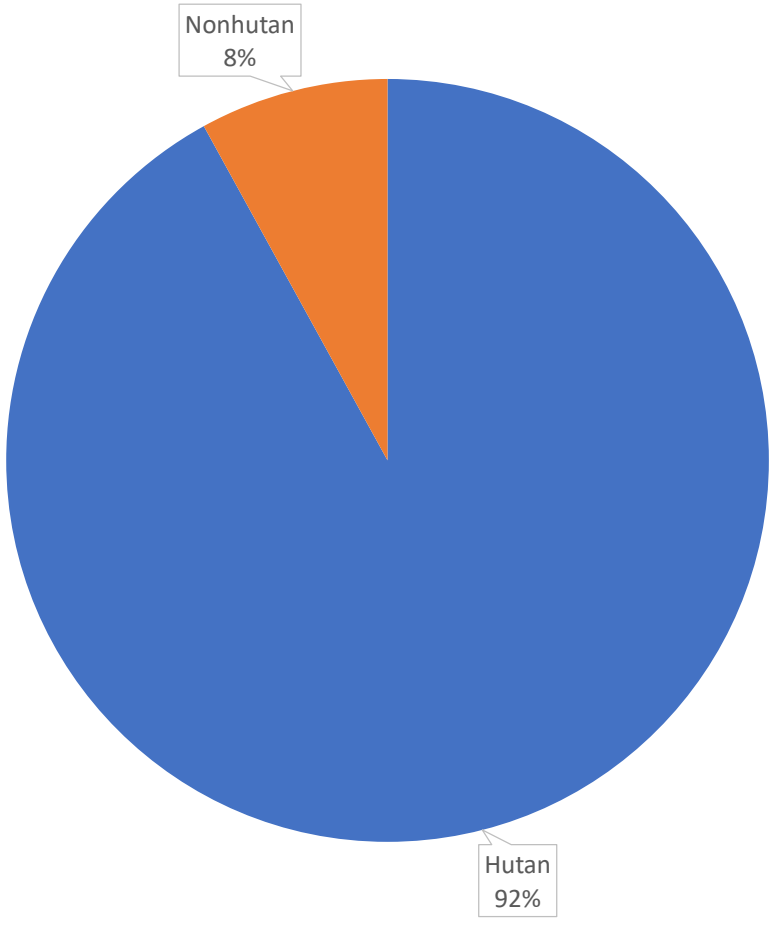

Gambar 6. Persentase (\%) Penutupan Lahan Hutan dan Nonhutan Tahun 2017

Tabel 5.

Data Aktivitas atau Perubahan Tutupan Lahan Tahun 1990-2017 menurut Kementerian Lingkungan Hidup dan Kehutanan

\begin{tabular}{|c|c|c|c|c|c|c|c|c|c|c|c|c|c|c|}
\hline \multirow{2}{*}{\multicolumn{3}{|c|}{$\begin{array}{c}\text { Deforestasi } \\
\text { Tahun 1990-2017 }\end{array}$}} & \multicolumn{12}{|c|}{ Tutupan Lahan 2017 KLHK } \\
\hline & & & B & Pk & $\mathrm{Pm}$ & $T$ & $s$ & A & $\mathrm{Br}$ & Pt & Pc & $\mathrm{Tr}$ & Tb & \\
\hline & & Kode & 2007 & 2010 & 2012 & 2014 & 3000 & 5001 & 20071 & 20091 & 20092 & 20122 & 20141 & (ha) \\
\hline \multirow{6}{*}{$\begin{array}{c}\text { Tutupan } \\
\text { Lahan } \\
1990 \\
\text { KLHK }\end{array}$} & $\mathrm{Hp}$ & 2001 & 2.921 & & 459 & 427 & 8 & 41 & 290 & & 75 & 704 & 275 & 5.200 \\
\hline & $\mathrm{Hs}$ & 2002 & 3.444 & 9.576 & 460 & 444 & 222 & 5 & & 40 & 63 & 1.712 & & 15.965 \\
\hline & $\mathrm{Hmp}$ & 2004 & 84 & & 37 & & & 18 & & & & & & 139 \\
\hline & $\mathrm{Hrp}$ & 2005 & 450 & & & 66 & 73 & 1 & 267 & & & & & 857 \\
\hline & $\mathrm{Hms}$ & 20041 & 378 & & & 1 & & 21 & 5 & & & & & 404 \\
\hline & Hrs & 20051 & 153 & & 26 & & & & 23 & & & & & 202 \\
\hline \multicolumn{3}{|c|}{ Luas (ha) } & 7.430 & 9.576 & 982 & 938 & 303 & 86 & 585 & 40 & 138 & 2.416 & 275 & 22.768 \\
\hline
\end{tabular}

Sumber: Kementerian Lingkungan Hidup dan Kehutanan (2017)

Keterangan: Hp = Hutan Primer; Hs = Hutan Sekunder; Hmp = Hutan Mangrove Primer; Hrp = Hutan Rawa Primer; Hms = Hutan Mangrove Sekunder; Hrs = Hutan Rawa Sekunder; B = Semak Belukar; Br = Semak Belukar Rawa; Pt = Pertanian Lahan Kering; Pc = Pertanian Lahan Kering Bercampur Semak; $\mathrm{Sw}=$ Sawah; $\mathrm{Tm}=$ Tambak; $\mathrm{A}=$ Tubuh Air; $\mathrm{Pm}=$ Pemukiman; Bdr = Bandara; $\mathrm{Tr}+$ Transmigrasi; $\mathrm{T}+$ Tanah Terbuka; $\mathrm{Tb}=$ Pertambangan; Pk = Perkebunan; $\mathrm{S}=$ Savana 
Tabel 6.

Jumlah Kehilangan Stok Karbon dan Emisi Karbon pada Tutupan Lahan di Kabupaten Teluk Bintuni

\begin{tabular}{|c|c|c|c|c|c|}
\hline $\begin{array}{c}\text { Jenis Perubahan } \\
\text { Lahan }\end{array}$ & Luas ha & $\begin{array}{c}\text { Stok Karbon } \\
\text { Tahunan tonC/ha }\end{array}$ & $\begin{array}{l}\text { Emisi Karbon } 27 \\
\text { Tahun ton } \mathrm{CO} 2 / \mathrm{ha}\end{array}$ & $\begin{array}{c}\text { Rata-Rata Stok } \\
\text { Karbon Per Tahun } \\
\text { tonC/ha }\end{array}$ & $\begin{array}{l}\text { Rata-Rata Emisi } \\
\text { Karbon Per Tahun } \\
\text { ton } \mathrm{Co} 2 / \mathrm{ha}\end{array}$ \\
\hline Deforestasi & 22.768 & 2.096 .034 & 7.686 .155 & 77.631 & 284.672 \\
\hline
\end{tabular}

Sumber: Kementerian Lingkungan Hidup dan Kehutanan (2017)

Tabel 7.

Potensi Kerugian Ekonomi dari Deforestasi dan Degradasi Hutan di Kabupaten Teluk Bintuni

\begin{tabular}{|c|c|c|c|c|c|c|c|}
\hline $\begin{array}{c}\text { Jenis } \\
\text { Perubahan } \\
\text { Lahan }\end{array}$ & $\begin{array}{c}\text { Stok Karbon } \\
\text { tonC/ha }\end{array}$ & $\begin{array}{c}\text { Harga } \\
\text { \$/tonC/ha }\end{array}$ & $\begin{array}{c}\text { Harga } \\
\text { Rp/tonC/ha }\end{array}$ & $\begin{array}{l}\text { Kerugian } \\
\text { (\$) }\end{array}$ & $\begin{array}{l}\text { Rata-rata } \\
\text { Kerugian } \\
\text { (\$) }\end{array}$ & $\begin{array}{c}\text { Kerugian } \\
\text { (Rp) }\end{array}$ & $\begin{array}{c}\text { Rata-rata } \\
\text { Kerugian } \\
\text { (Rp) }\end{array}$ \\
\hline Deforestasi & 3.035 .198 & 12 & 174.600 & 36.422 .374 & 1.348 .977 & 529.945.546.209 & 19.627 .612 .823 \\
\hline
\end{tabular}

Sumber: Data Primer (Hasil Analisis)

Keterangan: \$1 = Rp. 14.450,- (Saat Ini)

Tabel 5 tersaji data perubahan tutupan hutan atau deforestasi terbesar menurut Kementerian Lingkungan Hidup dan Kehutanan terjadi pada hutan sekunder luas sebesar 15.965 ha.

Tabel 6 menunjukkan data jumlah kehilangan karbon yang diakibatkan oleh deforestasi selama 27 tahun, yaitu sebesar 14.952.949 tonC/ha atau sebesar 85,98\%, dengan rata-rata kehilangan karbon per tahun adalah sebesar 553.813 tonC/ha. Sedangkan, jumlah emisi karbon dioksida selama 27 tahun adalah sebesar 54.832 .465 ton $\mathrm{CO} 2 /$ ha dengan rata-rata per tahun sebesar 2.030.832 ton $\mathrm{CO} 2$ / ha.

\section{Potensi Kerugian Ekonomi}

Potensi kerugian ekonomi dalam penelitian ini adalah potensi kerugian finansial daerah sebagai dampak terjadinya deforestasi di Kabupaten Teluk Bintuni selama 27 tahun. Nilai besaran kerugian diperoleh dengan cara mengalikan jumlah kehilangan stok karbon dengan harga karbon $\mathrm{Rp} /$ tonC/ha sesuai dengan Peraturan Menteri Kehutanan Republik Indonesia Nomor: P.36/Menhut-II/2009 tentang Tata Cara Perizinan Usaha
Pemanfaatan Penyerapan dan/atau Penyimpanan Karbon pada Hutan Produksi dan Hutan Lindung.

Hasil perhitungan yang disajikan pada Tabel 7 menunjukkan bahwa potensi kerugian ekonomi yang diakibatkan oleh deforestasi dan degradasi hutan di Kabupaten Teluk Bintuni selama 27 tahun sebesar Rp2.790.295.557.310,- dengan rata-rata kerugian per tahun sebesar Rp103.344.279.900,--

\section{Kesimpulan}

Tutupan hutan (forestland) di Kabupaten Teluk Bintuni yang mengalami perubahan luasan akibat deforestasi dari tahun 1990 sampai tahun 2017 adalah sebesar 22.768 ha atau sebesar $1 \%$ dari luas lahan, dengan perubahan luasan rata-rata per tahun sebesar 843 ha/tahun. Sehingga dapat disimpulkan bahwa laju deforestasi di Kabupaten Teluk Bintuni sekitar 1\%. Deforestasi yang terjadi pada kawasan hutan di Kabupaten Teluk Bintuni adalah akibat deforestasi terencana. Deforestasi yang diakibatkan adalah sebesar $76,7 \%$ dari total wilayah deforestasi. 
Selama periode 27 tahun ini, cropland merupakan tipe lahan non hutan yang mengalami peningkatan yang sangat besar, yaitu sebesar $8 \%$ atau seluas 13.601 ha dengan kenaikan luasan rata-rata per tahun sebesar 504 ha/Tahun. Sedangkan, grassland dan wetland mengalami penurunan luasan sebagai dampak peningkatan cropland. Penurunan ini masing-masing seluas 6.757 ha atau sebesar $3,25 \%$ dan 199 ha atau sebesar 5,47\% untuk kebutuhan lahan pertanian, pertambangan, perkebunan dan transmigrasi.

Jumlah stok karbon pada kawasan hutan di Kabupaten Teluk Bintuni tahun 2017 adalah sebesar 208.550.386 ton $\mathrm{C} / 2.036 .852$ ha dengan potensi emisi karbon dioksida sebesar 764.754.267 CO2/ha. Potensi kehilangan karbon sebagai dampak deforestasi selama 27 tahun adalah sebesar 14.952.949 ton C/ha atau sebesar $85,98 \%$ dengan rata-rata kehilangan karbon per tahun sebesar 553.813 ton $\mathrm{C} / \mathrm{ha}$. Jumlah emisi karbon dioksida selama 27 tahun sebesar 54.832.465 ton CO2/ha dengan ratarata per tahun sebesar 2.030.832 ton $\mathrm{CO} 2 /$ ha. Sementara potensi kerugian ekonomi yang diakibatkan oleh deforestasi di Kabupaten Teluk Bintuni selama 27 tahun adalah sebesar Rp2.790.295.557.310,- dengan rata-rata kerugian per tahun adalah sebesar Rp103.344.279.900,- dengan asumsi $\$ 1=$ Rp14.450,- saat ini.

\section{Ucapan Terima Kasih}

Terima kasih disampaikan kepada Badan Pemantapan Kawasan Hutan Wilayah XVII Manokwari Kementerian Lingkungan Hidup dan Kehutanan, Badan Perencanaan Pembangunan Daerah Kabupaten Teluk Bintuni dan Unit Pelaksana Teknis Geospasial Universitas Papua. Ucapan terima kasih khusus kepada Zulfikar Mardiyadi dan Agustinus
Murjoko staf pengajar Universitas Papua yang telah membantu menganalisis data. Para editor anonim yang sudah me-review dan memberikan saran perbaikan naskah tulisan ini.

\section{Referensi}

Badan Pemantapan Kawasan Hutan Wilayah XVII. (2017). Peta Penutupan Lahan Tahun 1990-2017 di Provinsi Papua Barat. Badan Pemantapan Kawasan Hutan Wilayah XVII.

Data Kompilasi dan verifikasi SKPD Terkait seluruh Kabupaten di Provinsi Papua Barat. (2014). Izin Perkebunan di Provinsi Papua Barat.

Data Kompilasi dan verifikasi SKPD Terkait seluruh Kabupaten di Provinsi Papua Barat. (2014). Izin Pertambangan di Provinsi Papua Barat.

Kementerian Lingkungan Hidup dan Kehutanan. (2015). Buku Kegiatan Serapan dan Emisi Karbon. Kementerian Lingkungan Hidup dan Kehutanan.

Margono, B. A., Potapov, P. V., Turubanova, S., Stolle, F., \& Hansen, M. C. (2014). Primary forest cover loss in Indonesia over 20002012. Nature Climate Change, 4(8), 730735.

https://doi.org/10.1038/ nclimate2277

WebGIS Kementerian Lingkungan Hidup dan Kehutanan. (2014). Izin Pengelolaan Hasil Hutan Kayu-Hutan Alam di Provinsi Papua Barat.

WebGIS Kementerian Lingkungan Hidup dan Kehutanan. (2014). Izin Pengelolaan Hasil Hutan Kayu-Hutan Tanaman di Provinsi Papua Barat. 